\title{
Non-native Teacher Talk as Lexical Input in the Foreign Language Classroom
}

\author{
Eunice Tang \\ Faculty of Education, the Chinese University of Hong Kong, Hong Kong, China \\ Email: tangeunice@cuhk.edu.hk
}

\begin{abstract}
Non-native or indigenous English teachers have provided the largest teaching and professional support in Asian countries where English is taught and learnt in school as an additional or international language. As the language environment outside classroom in these countries is generally poor, teachers become a major source of language input for learners. This article explores the Lexical Variation (LV) ratio of nonnative teacher talk and the percentage of words teachers used at different vocabulary levels to determine the lexical richness in a foreign language classroom. The classroom data revealed that teachers' oral input failed to provide a lexically rich environment as the teacher talk were limited in both variation and frequency range. Ways to enhance the lexical environment will be discussed.
\end{abstract}

Index Terms —non-native English teachers, lexical input, teacher talk, foreign language classroom

\section{INTRODUCTION}

Non-native or indigenous English teacher teaching English in non-English speaking environment is a common phenomenon in Asian countries, like China, Japan, Korea, Taiwan, Malaysia, Thailand, where English is taught and learnt as a compulsory school subject. They provided the largest teaching and profession support to the foreign language classroom. In China, it was estimated that there were 1.15 million full-time local foreign language teachers, of whom the majority of them were teaching regular English classes to 230 million full-time students at primary, secondary and tertiary levels ${ }^{1}$ (Educational Statistics Yearbook of China, 2007). The non-native or indigenous English teachers are the backbone of the teaching force. Native English teachers, on the other hand, are often considered as extra labour force or bonus to the language teaching environment. In Hong Kong, almost all primary and secondary schools have recruited 1 to 2 native English teachers to serve the whole school. However, these native English teachers are usually assigned to teach oral English only. School administrators are concerned about the cost of hiring expatriates as well as the contribution these native English teachers could make to prepare students for the high-stake examinations which characterizes the education system in this "Confucian-heritage culture" $(\mathrm{CHC})^{2}$ region. Although studies on the context of teaching of non-native English teachers are available (e.g. Watson \& Punjaporn, 2009; Haynes, 2009), the actual classroom practices of such a huge number of non-native English speakers teaching English in populated nonEnglish speaking environment in Asia are overlooked.

Theories of second language acquisition have claimed that language input has a consistent positive effect in improving proficiency. These theories maintain that the input has to be comprehensible to the learner and modified through interactions. In vocabulary acquisition, the Input Hypothesis (Krashen 1981, 1982) has inspired studies of incidental vocabulary learning through reading and listening and analysis of teacher's talk as oral input. Elley (1989) conducted an experiment with children aged seven to eight concerning incidental vocabulary acquisition from listening to stories. Elley found that these children, despite their varied ability, gained $15 \%$ of the vocabulary without teacher explanation and $40 \%$ with teacher explanation. The highest gains were nouns and there was less improvement with adjectives and verbs. This finding accords with belief about the imageability of words in dual-code theory (Paivio, 1986). The follow-up tests showed that the incidental vocabulary learning was relatively permanent. Elley identified three features that best predicted successful incidental vocabulary acquisition. They were the frequency of the word in the text, the depiction of the words in illustration and the amount of redundancy in the surrounding context. In a more recent study, Vidal (2003) studied first-year university EFL students on their academic listening of lectures as lexical input for vocabulary expansion. She found that listening to lectures resulted in vocabulary gain. Greater vocabulary gain was highly correlated with lecture comprehension, frequency of word occurrence, word elaborations and types of vocabulary. These studies threw light on incidental vocabulary acquisition from oral input, indicating that contextual variables, extent of elaboration, treatment of word and interactiveness are critical in determining whether teachers can produce effective language for incidental acquisition.

\footnotetext{
${ }^{1}$ English is the compulsory foreign language to be taken by all primary, secondary and undergraduate/college students in China.

2 According to Ho (1991), "Confucian-heritage cultures" refers to countries or educational systems which are influenced by and inherited the cultures of Confucian, e.g. China, Taiwan, Singapore, Hong Kong, Japan and Korea. See also Wong \& Wong (2004) and Biggs \& Watkins (1996) for the discussion of $\mathrm{CHC}$ classroom and learners.
} 
Teacher talk plays an important role in classroom organization and management, giving feedback and asking questions. It is generally agreed that language input provided by teacher is vital in second classroom for language development (Van Patten, 2003; Ellis, 2005). In China, teacher talk dominated the foreign language classroom (Tang, 2009). This could be explained by some pragmatic reasons. First, the large amount of teacher talk in Chinese classrooms matched the expectations of teachers, learners, schools and even parents (Li, 1999). Second, teacher talk is a natural outcome of traditional teaching practice, large class sizes, and low linguistic competence of the learners. Third, the curriculum, to a great extent, encourages teacher-centredness as it is the safest way of complying with the examination requirements and preparing students for the high stake public examinations. Thus, both the quantity and quality of teacher talk are valuable to learners as:

a) it provides a potentially valuable source for language input for acquisition.

b) it is unrealistic to reduce teacher talk time (TTT) as it is culturally inappropriate, where the classrooms are preoccupied with the traditional role of a teacher as knowledge-transmitter.

c) in an "input-poor" environment where the teacher is the principal source of lexical input, questions, nomination of topics, and interaction patterns initiated or shaped by the teacher affect exposure to the language.

d) the amount of input will affect the language learning outcomes (Mangubhai, 2005).

In China, the quantity and kinds of words to be acquired at different learning stages are stipulated in the English curriculum in the form of word lists. Teachers spend most of the class time to teach explicitly the "important" words, i.e. words highlighted by the textbook writers. However, Lado (1977, p.184), while commenting on West's A General Service List of English Words, pointed out that "it is also important to note that whenever these vocabularies have been taught in their entirety, the learners learn countless additional words and lexical units not found in the list". In other words, while teachers are explicitly teaching the target vocabulary items in the English lessons, they are at the same time creating a lexical environment for learners to "pick up" other words through the oral input.

\section{RESEARCH APPROACH}

\section{A. The Study}

In this study, the lexical environment in the English language classrooms in China was examined. These lessons were all conducted by non-native or indigenous English teachers. It aimed to find out if non-native teacher talk could provide a rich lexical environment in terms of the variety and frequency level of the teacher input for incidental vocabulary acquisition.

\section{B. Methodology}

Six teachers with five to ten years of teaching experience from three Chinese universities were invited to make a oneweek recording of their English teaching to the non-English major freshmen. The recorded lessons were transcribed. Teacher talk was analyzed to see the extent to which learners could benefit from oral input, and the extent to which it provided a lexically rich environment for incidental vocabulary acquisition. The focus rested on the variety and the frequency level of the teacher input.

TABLE 1:

\begin{tabular}{|l|l|l|l|l|l|}
\hline Teacher & Place & University & $\begin{array}{l}\text { Recording time } \\
\text { in minutes }\end{array}$ & Unit & $\begin{array}{l}\text { Total number of explicitly } \\
\text { treated words }\end{array}$ \\
\hline T-A & Shenzhen & key university & 200 & Bk. 2 Unit 9 & 94 \\
\hline T-B & Shenzhen & key university & 200 & Bk. 1 Unit 10 & 93 \\
\hline T-C & Guangzhou & non-key university & 240 & Bk. 2, Unit 4 & 71 \\
\hline T-D & Guangzhou & non-key university & 240 & Bk. 4, Unit 7 & 197 \\
\hline T-E & Beijing & key university & 240 & Bk. 3, Unit 1 & 48 \\
\hline T-F & Beijing & key university & 240 & Bk. 2, Unit 10 & 25 \\
\hline
\end{tabular}

[Source: Dong (ed.) 1997. College English: Intensive Reading (revised edition). Shanghai Foreign Language Education Press.]

The teacher talk was extracted from the lesson transcription and examined using the measure of lexical variation (LV) adopted by Meara, Lightbown and Halter (1997) and Brown, Sagers and LaPorte (1999) to assess the lexical richness of teacher talk. LV is the type-token ratio, and was chosen as an indicator of lexical richness because the calculation is straightforward, although it requires a clear definition of the terms "type" and "token":

$$
\mathrm{LV}=\quad \frac{\text { no. of types }}{\text { no. of tokens }} \quad \mathrm{x} 100
$$

In this study, 'types' were defined as all the different words in the corpus, and 'tokens' as the total number of running words. 'Type' was taken to include both the base form and all its derivations, despite any differences in orthography and pronunciation. The calculation was prepared with the aid of the WordSmith Tools 3.0 (Scott, 1998). Because the validity of the LV measure can be affected by differences in text length (Richards 1985; Laufer and Nation, 1995), a 
calculation based on the first 1,500 words of the teacher talk was also made to show more reliable and comparable LV scores.

The LV ratio alone does not give a full picture of lexical richness, however, as this requires additional consideration of word type frequency levels. Following Meara, Lightbown and Halter (1997), I matched the wordlists derived from each lesson transcript against basic 2,000 words from the British National Corpus (Leech, Rayson \& Wilson, 2001) and frequency lists available in the computer program VocabProfile (Nation 1986). The British National Corpus (BNC) was chosen because the 100 million-word corpus reflects the reality of today's English communication. The VocabProfile (VP) contains 3 sets of word list. first list (VP1) includes the most frequent 1,000 words of English; the second (VP2) includes the second 1,000 most frequent words, and the third (VP3) includes words not in the first 2,000 words of English, but frequent in upper secondary school and university texts from a wide range of subjects. All three lists include the base forms of words and derived forms. In this study, contractions such as "I'm", "how's" and "can't" were added to VP1 together with expressions commonly produced by Chinese speakers, such as "yeh", "ha", and "ah". (see Appendix A for words added toVP1).

\section{FINDINGS}

\section{A. Variety of the Lexical Input}

Table 2 below shows that the LV ratio of the six teachers varied greatly. Although the ratio rose in some individual lessons, this only reflected the instability of the ratio due to size of the corpus. The relatively low LV ratio implies that the teacher talk was not lexically rich. In other words, the fact that the foreign language learners are exposed to an "input-poor" environment is further substantiated. Learners not only have scarce exposure to the L2 outside classroom, they also have limited extensive exposure to the target language inside the classroom as well.

TABLE 2:

LEXICAL VARIATION OF INDIVIDUAL TEACHER

\begin{tabular}{|l|l|l|l|}
\hline LEXICAL VARIATION OF INDIVIDUAL TEACHER \\
\hline Teachers & Tokens & Types & LV ratio \\
\hline T-B & 6,373 & 1,046 & $16.41 \%$ \\
\hline T-C & 4,502 & 964 & $21.41 \%$ \\
\hline T-D & 1,848 & 509 & $27.54 \%$ \\
\hline T-E & 11,854 & 1,187 & $10.01 \%$ \\
\hline T-F & 7,689 & 1,150 & $14.96 \%$ \\
\hline
\end{tabular}

As mentioned, the difference in the length of the teacher talk or quantity of words in lessons has significant impact on the LV ratio. In order to validate the LV ratio and assure the reliability of the study, the first 1,500 words from each teacher were extracted for further analysis (Table 3). When the length of the corpus was limited to 1,500, the LV ratio of the six classes had relatively similar results, with Teacher B and Teacher E showing comparatively higher scores. The overall mean of the LV ratio of the six teachers was $28.70 \%$ which is comparable to the overall mean of the LV ratio of the nine teachers $(28.33 \%)$ observed in Meara, Lightbown and Halter's study.

TABLE 3:

LEXICAL VARIATION OF INDIVIDUAL TEACHER (WITH CORPUS OF 1,500 WORDS EACH)

\begin{tabular}{|l|l|l|l|}
\hline Teachers & Tokens & Types & LV ratio \\
\hline T-A & 1,500 & 420 & $28.00 \%$ \\
\hline T-B & 1,500 & 507 & $33.85 \%$ \\
\hline T-C & 1,500 & 400 & $26.85 \%$ \\
\hline T-D & 1,500 & 363 & $24.14 \%$ \\
\hline T-E & 1,500 & 527 & $35.27 \%$ \\
\hline T-F & 1,500 & 360 & $24.08 \%$ \\
\hline
\end{tabular}

Teacher D who taught the most vocabulary in the one-week lessons did not provide a rich lexical environment for learners to "pick up" other words from her speech. Yet, the large number of tokens and a low LV ratio suggest that there had been lots of repetition and recycling of words within the 240 minutes of lesson. Generally, the teacher was able to create a favourable acquisition environment for learners to encounter the words. It is not known, however, whether the new words were repeated more frequently than other, known, words.

\section{B. Frequency Levels of Lexical Input}

Although BNC is considered as a reliable source of reference to reflect modern English written and spoken communication, these basic words seemed to be underused to teach and communicate in the language classrooms of these six subjects. Series 2 in Figure 1 below represents the percentage of BNC words used by individual teacher. 


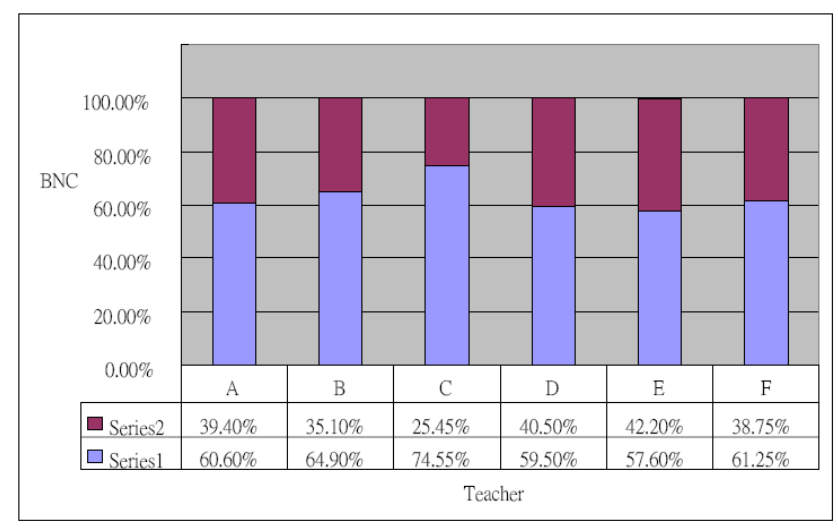

Figure 1: Percentages of BNC words in individual teacher talk

Teacher C who spoke the least in the whole week's lessons had the lowest percentage of BNC words, while Teacher $\mathrm{E}$ who had the highest LV ratio also had the highest percentage of BNC words. Among the six teachers, these basic words had served slightly half of the total different words used in the class (see Figure 2).

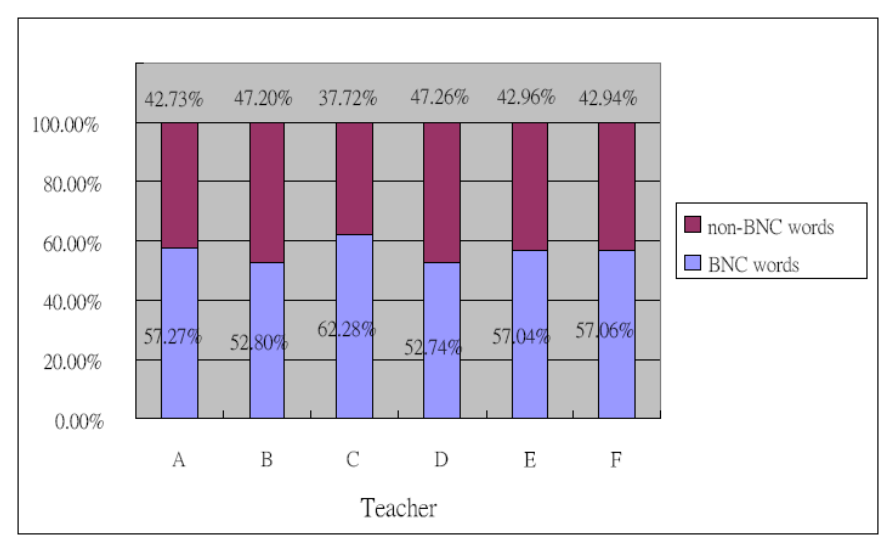

Figure 2: Percentages of words of individual teacher when compared with BNC

In order to have a closer examination of the kinds of words available from the oral input, the six teacher word lists were compared with the different levels of VocabProfile (Table 4 and Figure 3 below). All six teachers showed a greater proportion of words at VP1 and VP2, the first 2,000 most frequent words. Only 22\% of the words were at VP3 or beyond, of the type found in upper secondary school and university texts (see Appendix B for beyond VP3 words from Teacher C). The classroom did not seem to provide a lot of opportunities for an " $i+1$ " condition as "comprehensible input" (Krashen, 1981) for acquisition.

TABLE 4:

OVERALL WORD FREQUENCY LEVELS

\begin{tabular}{|l|l|l|}
\hline Frequency levels & Number of words & Percentage \\
\hline VP1 & 3,744 & $63.7 \%$ \\
\hline VP2 & 832 & $14.2 \%$ \\
\hline VP3 & 361 & $6.1 \%$ \\
\hline Sub-total & $\mathbf{4 , 9 3 7}$ & $\mathbf{8 4 \%}$ \\
\hline Beyond VP3 & 939 & $16 \%$ \\
\hline Total & $\mathbf{5 , 8 7 6}$ & $\mathbf{1 0 0 \%}$ \\
\hline
\end{tabular}




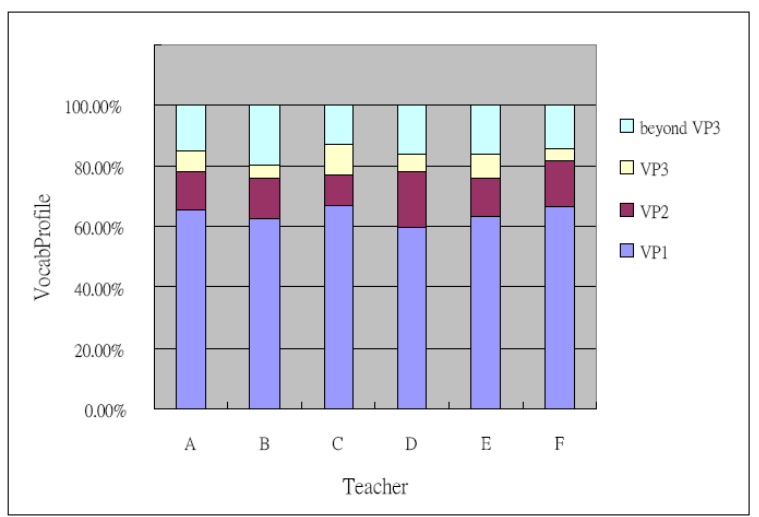

Figure 3: Percentages of words by frequency level of individual teacher

The majority of the words beyond VP3 level were from the textbooks, for example, sputnik, outraged, Luxembourg, which are glossed; grunt, dismay, embarrass, which are found in the textbooks and the word list prescribed in the national syllabus, and, professor, fantastic, bullet, which are not in the textbooks but are in the syllabus word list. The production of 'high-level' words relies very much on the wordlists in the textbooks and the syllabus.

There were a number of foreign names, such as Isaac Asimov, Oscar, and Francesco, and places, such as Lauderdale, Jacksonville, and Brunswick, in the word list beyond VP3. It is not surprising to find these unfamiliar proper names as all of the passages of the English textbooks are adapted from western publications. The disadvantage of this is that the contents are detached from both the teacher's and the learners' daily life and world knowledge. Fortunately, most of these proper names are glossed in the textbooks and the background information can be read to the learners from the teacher's book. The reason for learning these proper names is for the sake of comprehending the rest of the passage. It would probably be more appropriate to update the passages in the English textbooks so that learners could relate to the context and content more easily, however.

There are other words, like kidding, grumble, and nettalk, which do not appear in the textbooks nor the syllabus word list. These include topical proper nouns, such as Clinton, Madonna, Bananarama and pinyin and Chinese terms, such as, yuan (Chinese currency), ren (people), and Liang (Chinese surname). They appear when the teacher elaborates the word meaning or interacts with the learners. The occurrence of these words was closely linked with the way teachers taught the words and the delivery mode chosen by the teacher.

Using an expression coined by Krashen (1981), the teacher's speech was "roughly tuned". In other words, the teacher talk was approximately adjusted to the learners' foreign language development. This is different from "finely tuned" (Krashen, 1981) which involves interaction with dynamic adjustment of utterances arising from the conversation rather than simplicity in form and semantic redundance (Robinson, 1982 quoted in Ellis, 1984). As Tang and Nesi (2003) observed, interaction that triggers classroom dynamics includes student initiated vocabulary teaching and spontaneous talk between teacher and learners. This stimulates and encourages the production of 'high-level' words.

However, classroom discourse in CHC classroom is heavily teacher-led and is typical in large classes throughout the world. The discourse exemplifies a structured approach leading to the pedagogical goal - the teaching of the vocabulary item (see Example 1). Thus, non-topic related words do not usually occur as the explanation is focused, and in many cases, very brief, with interruptions from the learners to allow for diversity of topic and lexical variation.

Example 1: (Teacher E / Lesson 1)

T: ....... "Temporary", lasting only for a limited time, but if lasting for a long time or forever. What's the word? The opposite to temporary is permanent. I think in the last semester, we have learned this word. "permanent". "Stroll", walk at leisure, [stroll, promenade $]^{3}$. Walk slowly at leisure. And there's another word "wander". it means move about aimlessly, without purpose. "Stroll" [It means walking leisurely]. "Wander" [It means walking aimlessly]. "Commit", do something bad or unlawful. [make mistakes, how to say?] On the other hand, if the structure can be loosened to allow "freer explanation" and "interruptions", the classroom discourse changes and the lexical input will be changed accordingly. Example 2 below shows how the teacher attains the pedagogical goal of teaching "aptitude" while expanding the lexical input.

Example 2: (Teacher A / Lesson 1)

T: The first one, aptitude. It means natural ability or skill. Please pay attention to this, natural ability, it means what?

S: it's natural

T: Yeah. [it's natural]. You're born with aptitude. [There is "inborn", and something developed afterwards, how do you call that?]

\section{S: Skill.}

T: Skill? [There is another word for it, we have mentioned it before.] Ability? [it's a] general word. [We have mentioned another word, for example, when we talk about examination, competition. What kind of test is it?]

\footnotetext{
${ }^{3}$ The italicized words in square brackets in this paper are translation of the Chinese words.
} 


\section{S: Competence.}

T: Competence, right. Aptitude and competence. Aptitude is natural ability, but competence is the ability you developed after learning., after learning. O.K. For example, the English test, English competence test, is a test to test your ability of what---how well you have learned English, right? [This is not a natural aptitude of learning English. It's how well you have learned English.] How well you learn. [This is called] competence, aptitude [is some you were born with]. Now next word. Normal.

Example 2 above also illustrates another aspect of acquisition, which is the attention needed to realise the new input. Grounded on Noticing Hypothesis (Schmidt, 2000), learners must 'notice' critical features for acquisition to take place. Teacher A drew learners' attention to the new materials in the input by associating meaning with words, "aptitude" means "natural ability". She also asked learners' about the meaning of "natural ability", relating it to personal experience or prior knowledge when "competence" was introduced. Of course, there are other ways to draw learner's attention to the new input, for example, by associating sound with form and demanding higher cognitive activities such as the production of examples.

\section{L1 and L2 Use in the Foreign Language Classroom}

There has always been controversy about using L1 in the language classroom. Some argue that the use of the mother tongue will have positive effects on the learners and learning as they could be more focused on the demands of the task and could then be involved in higher quality discussion. It is argued that it reduces the learning load.

Elliott and Tao (1998) suggested that L1 translation is the most favourable teaching condition for recalling lexical meanings. Providing the L1 translation or eliciting the L1 translation seems to be equally sufficient and beneficial as aids to vocabulary retention.

However, the use of L1 in the language classroom deprives the learner of opportunities for exposure to the target language and practice in a simulated environment. In the Chinese classroom, the use of L1 in teaching seems to depend on the teachers, their teaching style and belief and even on the language competence of the teacher, rather than on the ability of the learners. For example: Teacher D is teaching in a non-key university which accepts average learners. She claimed that her learners have a low standard of English and low motivation. She used the most target language in the classroom. Teachers $\mathrm{E}$ and $\mathrm{F}$ are both teaching in a prestigious key university in the capital Beijing. Their learners have above average scores in the National Matriculation English Test, but their English classes were not conducted entirely in the target language.

There are signs in the data that teachers tended to rely quite heavily on L1 as a classroom language. This is shown in Table 5. The L1 was used as much as the L2 and for some teachers, for example, Teachers A and C, L1 was used as principal language in English lessons.

TABLE 5:

TEACHERS' CHOICE OF LANGUAGE

\begin{tabular}{|l|l|l|l|l|l|}
\hline Class & Class time & Tokens in English & Tokens in Chinese & $\begin{array}{l}\text { Number of English words } \\
\text { per minute }\end{array}$ & $\begin{array}{l}\text { Number of Chinese } \\
\text { words per minute }\end{array}$ \\
\hline T-A & 200 & 6,373 & 8,584 & 63.73 & 85.84 \\
\hline T-B & 200 & 4,502 & 3,906 & 45.02 & 39.06 \\
\hline T-C & 240 & 1,848 & 3,491 & 15.38 & 29.10 \\
\hline T-D & 240 & 11,854 & 5,146 & 98.78 & 42.88 \\
\hline T-E & 240 & 4,459 & 4,234 & 37.16 & 35.29 \\
\hline T-F & 240 & 7,689 & 5,573 & 64.08 & 46.44 \\
\hline
\end{tabular}

The reliance on L1 in the classroom raises the question of the teachers' ability to explain vocabulary in English and their general command of the language. It could be an alarming indication of the teachers' lack of proficiency. Example 3 below shows how L1 was used in teaching the word "chop" to the learners. The teacher first tried to relate the new word to another word "chopstick". However, the learners could not give her the correct L1 equivalent. So, the teacher decided to teach both "chop" and "chopstick". She used L1 to give an illustrative example of "chop", then she switched to L2 for its parts of speech and L1 again for the translation. In teaching "chopstick", the teacher first gave an illustrative situation in L2. Then, she stopped the elaboration and decided to provide the L1 meaning of the word "chopstick" instead.

Example 3: (T-D-1)

529 T: Next one, chop. Do you know, do you know chopstick? Do you know this word? Do you know chopsticks? 530 Ss: [stick]

531 T: Chopstick? Do you know chop? [The flesh attaches to the bone. This ... this means sparerib.] Yes? As a... a ...a noun, it [sparerib] or [chop]. As a verb, also means [chop]. Chopsticks, what's the meaning of chopsticks? This one is... er... are produced in China. Asian people use chopsticks--- [chopstick].

This switch of language could possibly suggest that the teacher felt more comfortable using L1 for extended speech or complicated ideas and L2 for brief and short utterances. Of course, the teacher could make decisions about language choice because of other reasons, such as the pace of teaching, learners' requests (if there are any), etc.

Although experimental evidence has suggested that excessive explanation often resulted in learner incomprehension (Chaudron, 1982), in Example 3 above, the teacher could have elaborated further in the L2 as the context and the 
meaning had already been made clear to the learners. The use of the target language allows repeated encounters with known words and increases exposure to unknown words. The over-reliance on the L1 deprives learners of access to the target language.

Furthermore, if providing the L1 equivalent becomes an established practice it seems likely that learners will "switch off" when the teaching is done in the L2 as they know that the L1 meaning will be provided anyhow. Heavy reliance on the L1 discourages learners from listening and processing in the target language. If most of the vocabulary items are "picked up" during exposure to the target language, this "switching off" mechanism will close the channel to incidental learning.

Also, as there is often no direct L1 equivalent for the target word, simply providing the L1 translation will lead to distortion of meaning and inappropriate use in the communicative context. It is certainly not reliable to assume that knowledge of the L1 equivalent indicates acquisition of the new word.

\section{Learners' Output}

It is thought that 'good' teacher talks less as too much teacher talk time (TTT) will deny learners opportunities to speak (Cullen, 1998). However, it could be a fallacy that when the teacher speaks more, it will automatically minimize learners' chance of participation. Teacher F spoke as much as the other teachers did in the lessons, but the learners in her class were able to vocalize and to take part in the learning process. In her lessons, she deliberately spared time at the beginning of the lessons for learners to talk freely about any topics, so the learners' output was raised.

The degree of participation is calculated on the basis of the total number of tokens from learners' speech, regardless of the language medium, over the total contribution of tokens from the teacher and learners. The higher the percentage, the more opportunities the learners have to participate in class. Most studies use the amount of time as a measure of the TTT as proportion of time allowed for learners to participate. However, the classroom data in China did not reveal any individual or group activities. It is, therefore, unreliable to measure the time as an indicator of degree of participation. In this study, the token, regardless of the medium, is adopted as a measurement tool to reflect the TTT and learners' participation.

In most classes, learners' output was minimal (Table 6). This suggests that the classroom does not allow adequate “comprehensible output", as proposed by Swain (1985) for acquisition. Also, the learners' contribution included mainly choral pronunciation practice and individual responses. Participation through interaction with the teacher or among learners was rare. There was no way to try out new rules and acquire new language through output.

TABLE 6:

LEARNERS' OUTPUT

\begin{tabular}{|c|c|c|c|c|}
\hline Class & Teachers (Tokens) & Tokens in English & Tokens in Chinese & $\begin{array}{l}\text { Degree of participation } \\
(\%)\end{array}$ \\
\hline $\mathrm{A}$ & 9,212 & 393 & 206 & 6.1 \\
\hline $\mathrm{A}$ & 5,745 & 294 & 513 & 12.3 \\
\hline $\mathrm{B}$ & 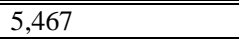 & 229 & 188 & 7.1 \\
\hline $\mathrm{B}$ & 2,941 & 1,270 & 1,075 & 44.4 \\
\hline$\overline{\mathrm{C}}$ & 2,794 & 193 & 1 & 6.5 \\
\hline $\mathrm{C}$ & 2,545 & 15 & 46 & 2.3 \\
\hline$\overline{\mathrm{D}}$ & 7,492 & 676 & 255 & 11.1 \\
\hline $\mathrm{D}$ & 9,508 & 543 & 34 & 5.7 \\
\hline $\bar{E}$ & 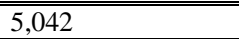 & 222 & 20 & 4.6 \\
\hline $\mathrm{E}$ & 3,652 & 668 & 610 & 26 \\
\hline$\overline{\mathrm{F}}$ & 8,237 & 2,134 & 67 & 21.1 \\
\hline $\mathrm{F}$ & 5,025 & 2,562 & 53 & 34 \\
\hline
\end{tabular}

\section{DISCUSSION}

This study of English vocabulary input focused on the quality and quantity of oral input from the teachers. The analysis of teacher talk is done with the purpose of reflecting the reality of the classroom and suggesting appropriate and attainable models for language teachers to follow within the classroom context on the other hand. The measure of LV and frequency levels suggests that the Chinese classroom in terms of quantity and quality is lexically impoverished. Teacher talk provides some sort of lexical environment for acquisition, but it is not a rich one.

As Krashen (1982) asserted, the more the communication in the classroom environment is approximated to the real world, the greater the extent of acquisition. In other words, the best lexical environment is a virtual representation of the natural language setting. However, the language that the teachers used was "caretaker" language and the interaction was limited to display questions only. Learners had no opportunities to negotiate meaning. The EFL classroom is not an "acquisition-rich" setting at all and input from teachers is not the best kind of lexical input for acquisition. The classroom does not provide an environment for natural exposure. It is an artificial one, with the special features of classroom language. Teachers use simple language and vocabulary. The choice of words is also restricted because of the limited functions that could possibly take place in the classroom. 
One way to deal with the issue of the impoverished lexical environment in the classrooms observed in this study is to see the vocabulary instructions and lexical environment as problems and approach them with the need for change and innovation. In order to improve the lexical environment, it is necessary to expand the topics, vary the teaching skills and enrich the interaction. Bowers (1980 quoted in Malamah-Thomas 1987) listed six contexts for verbal behaviour of the teacher in the classroom. They are: questioning/eliciting; responding to learners' contributions; presenting/explaining; organizing/giving instructions; evaluating/correcting; socialising/establishing and maintaining classroom rapport. These contexts are not new to any teachers but the potential of allowing teachers to create more lexical input should not be ignored. Attempts to negotiate meaning with learners and create opportunities for learners to interrupt can open more opportunities to wider lexical variety.

A richer lexical environment requires conscious effort from the teachers to allow more teacher-learner interaction, more topics nominated by the teachers or learners and more spontaneous exchanges. Observation of classroom activities and occurrences of "high-level' words in the data suggests that only when teachers use the target language more often, explaining words with elaboration, and interacting with learners, can a rich and varied lexical environment be created. Laufer \& Hulstijin (2001) stressed the importance of devising learning tasks to induce more involvement load for successful incidental vocabulary learning. According to Laufer \& Hutstijin, teacher should design learning task which can induce different combination of the involvement factors "needs", "search" and "evaluation" for each word. The more factors involved in one word, the greater involvement load they generate and better retention can be achieved. Kasper (2001) insisted that language socialization is an integrate part of second/foreign language teaching. However, it relies on teachers' cultural, pragmatic and interactional expertise in the language. When no or minimal interaction is allowed in the class, the number of words and the types of words from teachers will have a significant impact on vocabulary acquisition.

To create a rich lexical environment, one of the major issues is the choice of language. The foreign language classroom led by non-native or indigenous English teachers tend to adopt mother tongue to improve the efficiency of teaching. The reliance on L1 impedes a rich lexical environment for incidental acquisition and teacher talk lacks variety and high-level words. Their speech, under appropriate conditions of comprehensible input, could promote incidental vocabulary acquisition. However, this does not seem to be a major concern of teachers. Their mindset remains on helping the learners to acquire the glossed words in the textbooks to meet the vocabulary requirements in the mandatory national examination. The mindset of helping learners to learn most words within the limited class time through L1 also fails to allow learners to 'notice' the features of L2 input for successfully language learning. The potential of the teacher as a source of lexical input is overlooked.

The data have also shown that the L1 was used not only for explaining vocabulary items but also as a medium to communicate with the learners. The heavy reliance on L1 can be regarded as an indication of lack of variety of teaching methods or teaching skills. It can be an alarming signal of the lack of proficiency of the teacher and of inadequate training. It is also worth developing the reflective thinking ability of the teacher to raise the quality and not just the quantity of teacher talk. Teachers can build on redundancy in L2 and use less L1 while explaining the words. They can critically analyze their taped lessons to raise their awareness of the use of lexis, the vocabulary teaching methods and the language use in the classroom. They can make a list of teaching strategies which enable more oral lexical input but not necessarily reduce the learners' output and their chance of participation.

Teacher talk could also be introduced to the teacher training programme to establish a solid and sound knowledge and ability to enrich the quality of their speech for a rich lexical environment.

To regulate the input-poor environment, there is a need to expand the exposure to the target language. Setting up English corner at school, data bank of vocabulary on the web, electronic English books can all be helpful to allow more intentional or incidental learning.

\section{CONCLUSION}

Overall, it seems apparent from the classroom data that teacher talk from non-native or indigenous English teachers could not provide a rich lexical environment for incidental vocabulary acquisition in the foreign language classroom. However, we also see a high potential of teacher talk as lexical input. It has to be stressed that it is not the intention of this paper to evaluate the non-native or indigenous English teachers. On the contrary, this is an attempt to value the contributions of this large labour force who are instructing probably the greatest number of English learners in the world.

APPENDIX A: WORDS ADDED TOVP1 


\begin{tabular}{|llllll|}
\hline ah & en & hm & ok & they've & why's \\
aha & er & hmmm & okay & un & won't \\
ain't & er & how's & one's & wasn't & wouldn't \\
aren't & err & huh & other's & we'd & wow \\
can't & err & huh & shan't & we'll & ya \\
can't & ha & I'd & she'd & we're & yah \\
couldn't & ha & I'll & she'll & weren't & yap \\
couldn't & hadn't & I'm & she's & we've & yea \\
didn't & hah & isn't & shouldn't & what's & yeah \\
doesn't & hasn't & it's & that's & what's & yeh \\
don't & haven't & I've & there's & where's & you've \\
eh & he'd & la & they'd & which's & you'd \\
eha & h'll & let's & they'll & who's & you'll \\
em & he's & mm & they're & whom's & you're \\
\hline
\end{tabular}

APPENDIX B: BEYOND VP3 WORDS FROM TEACHER C

\begin{tabular}{|l|l|l|}
\hline (T-C) - 68 words & & \\
\hline ADJ & GRUNT & ROSES \\
ALGEBRA & HEADMASTER & SANDYCOLOURED \\
BLOODSHOT & HYDROGEN & SENIOR \\
BOOTLACE & INCOMPETENT & SETUP \\
BRITAIN'S & INDIGNITY & SHRUB \\
CABBAGE & -ING & SHRUBS \\
CAMEL'S & JOHN & SHY \\
CARPET & JUNIOR & SHYLY \\
CERTIFICATE & LACE & SLENDER \\
COLONEL & -LY & SLIM \\
CONJ & METER & STALE \\
CONSUL & MOBILEPHONE & UNBEARABLE \\
COUPLE & MOUSTACHE & UNDID \\
CRICKET & MUMBLE & UNDO \\
CRUMB & ONESELF & UNDOING \\
DISMAY & PARAGRAPH & UNDONE \\
DISMAYED & PEOPLE'S & UNDO'S \\
EVERGREEN & PHRASE & UNSTREAMED \\
EXAM & PHRASES & VISA \\
FOREHEAD & PLUS & WAISTED \\
FUME & PREDECESSORS & WINKLED \\
GRAVEL & PROSPECT & WRITER'S \\
GRUMBLE & RANGING & \\
\hline
\end{tabular}

\section{REFERENCES}

[1] Biggs, J. \& Watkins, D. (1996). The Chinese Learner in Retrospect. In Watkins, D.A. and Biggs, J.B. (Eds.) The Chinese Learner: Cultural, Psychological and Contextual Influences. Hong Kong and Melbourne: Comparative Education Research Centre and The Australian Council for Educational Research Ltd, pp.269-285.

[2] Bowers, R. (1980). Verbal behaviour in the language teaching classroom. Unpublished PhD thesis, Reading University.

[3] Brown, C., S. Sagers and C. LaPorte. (1999). Incidental vocabulary acquisition from oral and written dialogue journals. In M. Wesche and T. S. Paribakht (eds.). Incidental L2 Vocabulary Acquisition: theory, current research, and instructional implications. Cambridge University Press.

[4] Chaudron, C. (1982). Vocabulary Elaboration in Teachers' Speech to L2 Learners. Studies in Second Language Acquisition, 4(2), 170-180.

[5] Cullen R. (1998). Teacher talk and the classroom context. ELTJ, 52(3), 179-187.

[6] Department of Development and Planning, Ministry of Education. (2007). Educational Statistics Yearbook of China 2007. Beijing: People's Education Press.

[7] Elliott, R.T. and V. Tao. (1998). The effect of four learning conditions on short-term recall of lexical meaning. Educational Research Journal, 13(1), 63-84.

[8] Ellis, R. (1984). Classroom second language development. Oxford: Pergamon Press.

[9] Ellis, R. (1995). Modified oral input and the acquisition of word meanings. Applied Linguistics. 16(4), .409-441.

[10] Ellis, R. (2005). Principles of instructed language learning. System, 33(2), 209-224.

[11] Elley, W. B. (1989). Vocabulary acquisition from listening to stories. Reading Research Quarterly, 24(2), 174-187.

[12] Haynes, D. (2009). Non-Native English-Speaking Teachers, Context and English Language Teaching. System, 37(1), 1-11

[13] Huang, Z.H. (1999). The impact of globalisation on English in Chinese universities. In D. Graddol and U.H. Meinhof. (eds.) English in a changing world. Guildford: Biddles Ltd, pp. 79-88.

[14] Kasper, G. (2001). Four perspectives on L2 pragmatic development. Applied Linguistics, 22(4), 502-530.

[15] Krashen, S. (1981). Second Language Acquisition and Second Language Learning. Oxford: Pergamon.

[16] Krashen, S. (1982). Principles and Practice in Second Language Acquisition. Oxford: Pergamon.

[17] Lado, R. (1977). Language Testing. London: Longman. 
[18] Laufer, B. \& P. Nation. (1995). Vocabulary Size and Use: Lexical Richness in L2 Written Production. Applied Linguistics, $16(3), 307-322$

[19] Laufer, B \& Hulstijin, J. (2001). Incidental vocabulary acquisition in a second language: the construct of task-induced involvement. Applied Linguistics, 22(1), 1-26.

[20] Leech G., Rayson, P., \& Wilson, A. (2001). Word frequencies in written and spoken English: based on the British National Corpus. Harlow: Longman.

[21] Long, M. H. (1981). Input, interaction and second language acquisition. In H. Winitz (ed.), Native Language and Foreign Language Acquisition. Annals of the New York Academy of Sciences, 379, 259-278.

[22] Long, M. H. (1983). Does second language instruction make a difference? A review of research. TESOL Quarterly, 14, 378390.

[23] Li, S. Y. (1999). On the effectiveness of teacher talk in the ELT classroom. Teaching English in China. Issue 36. Foreign Language Teaching and Research Press, pp.11-16.

[24] Malamah-Thomas, A. (1987). Classroom Interaction. Oxford: Oxford University Press.

[25] Mangubhai, F. (2005). What can EFL Teachers Learn from Immersion Language Teaching?. Asian EFL,7(4), $203-212$.

[26] Meara, P., P. Lightbown \& R. Halter. (1997). Classrooms as Lexical Environments. Language Teaching Research, 1(1), $28-47$.

[27] Nation, I.S.P. (1986). Vocabulary Lists. Occasional Publication No.17. English Language Institute, Victoria University of Wellington.

[28] Nunan, D. (1990). The questions teachers ask. JALT Journal. 12(2), 187-202.

[29] Paivio, A. (1986). Mental representations: a dual coding approach. Oxford. England: Oxford University Press.

[30] Richards, J.C. (1985). Lexical knowledge and the teaching of vocabulary. The Context of Language Teaching, Oxford: Oxford University Press. pp.176-188.

[31] Schmidt, R. (2000). Attention. In P. Robinson (ed.), Cognition and Second Language Instruction. Cambridge: Cambridge University Press.

[32] Scott, M. (1998). WordSmith Tools 3.0. Oxford: Oxford University Press.

[33] Swain, M. (1985). Communicative competence: some roles of comprehensible input and comprehensible output in its development. In S.M. Gass and C.G. Madden (Eds.), Input in Second Language Acquisition. Rowley, MA: Newbury House.

[34] Tang E. and H. Nesi. (2003). Teaching vocabulary in two Chinese classrooms: intensive and extensive exposure in Hong Kong and Guangzhou. Language Teaching Research. 7(1), 65-97.

[35] Tang, E. (2009). A cultural framework of "Chinese learn English": a critical review of and reflections on research. Journal of English as an International Language. 4:7-43.

[36] Van Patten, B. (2003). From input to output: A teacher's guide to second language acquisition. New York: McGraw-Hill.

[37] Vidal, K. (2003). Academic listening: a source of vocabulary acquisition? Applied Linguistics, 24(1), 56-89.

[38] Watson, T. \& Punjaporn, P. (2009). Implicit Attitudes towards Native and Non-Native Speaker Teachers. System, 37(1), 23-33

[39] Wong, N. Y. \& Wong, W. Y. (2002). The "Confucian Heritage Culture" learner's phenomenon. Asian Psychologist, 3(1), 7882.

Eunice Tang is an Assistant Professor at the Faculty of Education, The Chinese University of Hong Kong. She completed her $\mathrm{PhD}$ in English Language Teaching at the University of Warwick. Her research interests include technology in teacher education, vocabulary, and professional teacher development. Her recent publications include: i) Introduction and Development of a Blog-Based Teaching Portfolio: A case study in a pre-service teacher education programme. International Journal of Learning. 16, (8), 89-100. (2009); ii) Studying lexical input from ESL textbooks for primary and junior secondary students: a case study in Hong Kong. The Journal of Asia TEFL, 6(3), 35-58. (2009); iii) A cultural framework of "Chinese learn English": a critical review of and reflections on research. Journal of English as an International Language. 4:7-43. (2009) 